J Pest Sci

DOI 10.1007/s10340-008-0225-X

ORIGINAL PAPER

\title{
Weed emergence as influenced by soil moisture and air temperature
}

\author{
José M. G. Calado · Gottlieb Basch • Mário de Carvalho
}

Received: 18 March 2008 / Revised: 3 September 2008 / Accepted: 25

September 2008

(c) Springer-Verlag 2008

\begin{abstract}
Emergence of weed seedlings depends on soil environmental conditions; mainly temperature and moisture, with the latter being fundamental and particularly important in environments which are characterised by irregular amounts and distribution of rainfall throughout the year. Thus, this study looks at the influence of soil moisture and air temperature on the emergence of weed seedlings. The experiment was carried out under controlled environmental conditions, using rings filled with samples of undisturbed topsoil $(0-2.5 \mathrm{~cm}$ and $0-5 \mathrm{~cm}$ deep) of a Luvisol. There were four moisture levels that were maintained constant, with several repetitions (16-20). The results indicate that the maximum population density of weed plants was obtained with soil moisture near field capacity. With regard to the depth of the soil containing the seeds which contributed towards optimising population density, it was noted that the first $2-3 \mathrm{~cm}$ of undisturbed soil were critical for maximising the population. The emergence of seedlings was modelled using data from the five centimetre topsoil with soil moisture close to field capacity. This model indicates that a mean daily temperature sum of $446{ }^{\circ} \mathrm{C}$, which under Mediterranean autumn conditions represent a period of approximately one month, is needed, in order to obtain $80 \%$ of potential autumnwinter plant density, relative to the observed potential.
\end{abstract}

Keywords Emergence $\cdot$ Population density $\cdot$ Potential population $\cdot$ Weeds

Communicated by M. Traugott.

J. M. G. Calado (\&) · G. Basch · M. de Carvalho

Crop Science Department, University of Évora, Apartado 94, 7002-554 Évora, Portugal

e-mail: jcalado@uevora.pt; jcalado@dWt.uevora.pt

J. M. G. Calado · G. Basch • M. de Carvalho

Institute of Mediterranean Agricultural Sciences (ICAM), Apartado 94, 7002-554 Évora, Portugal 